\title{
Percepção da felicidade e bem-estar nos acadêmicos de uma instituição de ensino superior particular no Estado do Tocantins, Brasil
}

\author{
Perception of happiness and well-being in academics from a private higher education institution in \\ the State of Tocantins, Brazil \\ Percepción de felicidad y bienestar en académicos de una institución privada de educación superior \\ en el Estado de Tocantins, Brasil
}

Nadiele Ferreira Monteiro ORCID: https://orcid.org/0000-0002-5896-1272 Faculdade Guaraí, Brasil

E-mail: nadiele.mae@gmail.com

Yasmin Almeida Brito

ORCID: https://orcid.org/0000-0002-8216-1996 Faculdade Guaraí, Brasil E-mail: yasmin.almeida@hotmail.com Adriana Keila Dias

ORCID: https://orcid.org/0000-0003-1291-5593 Faculdade Guaraí-FAG, Brasil E-mail: adrianakeiladias@hotmail.com

Giullia Bianca Ferraciolli do Couto ORCID: https://orcid.org/0000-0002-9768-778X Faculdade Guaraí, Brasil

E-mail: giulliabianca@ hotmail.com

Reobbe Aguiar Pereira ORCID: https://orcid.org/0000-0003-2578-2611 Faculdade Guaraí, Brasil

E-mail: enfreobbe@gmail.com

Camilla Teles Alencar ORCID: https://orcid.org/0000-0002-5767-9267 Faculdade Guaraí, Brasil

E-mail: camillatalencar@gmail.com Glaucya Wanderley Santos Markus ORCID: https://orcid.org/0000-0001-8916-1086 Faculdade Guaraí, Brasil

E-mail: glaucyamarkus@outlook.com

\begin{abstract}
Resumo
A educação superior promove um ambiente repleto de mudanças para os acadêmicos. Este estudo tem como objetivo em avaliar a percepção de felicidade e bem-estar nos acadêmicos de uma instituição de ensino superior particular no Estado do Tocantins, Brasil. Trata-se de uma pesquisa exploratória e descritiva, com análise qualiquantitativa, onde buscou-se melhor entendimento sobre a percepção da Felicidade e Bem-estar, a pesquisa constitui com 104 acadêmicos do Instituto Educacional Santa Catarina/ Faculdade Guaraí- IESC/FAG. A amostra foi constituída por $61 \%$ de acadêmicas do sexo feminino, $35 \%$ do sexo masculino e 5\% declaravam-se de outro sexo, com idade variando < 20 e > 30 anos. Os resultados mostraram que a maioria dos acadêmicos apresentaram uma boa qualidade de vida indicando associação ao desempenho e sucesso acadêmicos, aspectos relacionados. Isso mostra que as instituições devem realizar interferências asseguradas principalmente nas características dos cursos e de seus formandos e reforçar a importância de projetos pedagógicos com desenvolvimento psicossocial.
\end{abstract}

Palavras-chave: Faculdade; Expectativas; Qualidade de vida.

\begin{abstract}
Higher education promotes an environment full of change for academics. This study aims to assess the perception of happiness and well-being among students from a private higher education institution in the State of Tocantins, Brazil. This is an exploratory and descriptive research, with qualiquantitative analysis, which sought to better understand the perception of Happiness and Well-being, the research consists of 104 academics from the Santa Catarina Educational Institute/ Faculdade Guaraí- IESC/FAG. The sample consisted of $61 \%$ female students, 35\% male and 5\% declared themselves to be of the other sex, aged between $<20$ and $>30$ years. The results showed that most students had a
\end{abstract}


good quality of life, indicating an association with academic performance and success, which are related aspects. This shows that institutions must carry out guaranteed interference, mainly in the characteristics of the courses and their graduates, and reinforce the importance of pedagogical projects with psychosocial development.

Keywords: College; Expectations; Quality of life.

\section{Resumen}

La educación superior promueve un entorno lleno de cambios para los académicos. Este estudio tiene como objetivo evaluar la percepción de felicidad y bienestar entre estudiantes de una institución privada de educación superior en el estado de Tocantins, Brasil. Se trata de una investigación exploratoria y descriptiva, con análisis cualitativo, que buscó comprender mejor la percepción de la Felicidad y Bienestar, la investigación consta de 104 académicos del Instituto Educativo Santa Catarina / Faculdade Guaraí- IESC / FAG. La muestra estuvo constituida por un $61 \%$ de alumnas, un 35\% de varones y un 5\% se declaró del otro sexo, edad entre <20 y 30 años. Los resultados mostraron que la mayoría de los estudiantes tenían una buena calidad de vida, lo que indica una asociación con el rendimiento académico y el éxito, aspectos relacionados. Esto demuestra que las instituciones deben realizar una interferencia garantizada, principalmente en las características de los cursos y sus egresados, y reforzar la importancia de los proyectos pedagógicos con desarrollo psicosocial.

Palabras clave: Facultad; Expectativas; Calidad de vida.

\section{Introdução}

A educação superior tem sido motivo de discussões e debates pelas mudanças que vem sofrendo, caracterizado pelo crescimento de oportunidades de ingresso no ensino superior. Ao ingressar em uma instituição de ensino superior, são trazidas expectativas e perspectivas, que sejam tanto positivas quanto negativas, geralmente acompanhadas por sentimentos de ansiedade, medos, dúvidas e anseios (Campos, 2016).

Na universidade, encontros de diferentes culturas é representado não somente pelos acadêmicos que porventura, venham de outras cidades, mas principalmente por aqueles vindos de diferentes regiões, famílias e culturas, o que sugere mudanças e uma adaptação a essa realidade, que pode gerar emoções como depressão, ansiedade, tensão, aborrecimento, desejo e medo, que acabam afetando e interferindo no desempenho acadêmico e nas atividades educativas (Barros Fiho \& Karnal, 2016).

Para Davok \& Bernard (2016), conhecer as perspectivas e expectativas do aluno permite identificar as prováveis causas relacionadas a evasão no curso escolhido, bem como, subsidiar informações para o planejamento de políticas e planos institucionais que visem a permanência e melhor aproveitamento no ensino, pesquisa e extensão oferecidos pela universidade.

Os indivíduos agem como atores emocionais, produzida pelo governo do discurso positivo, procurando trabalhar seus sentimentos com o objetivo de obter ganhos pessoais, direcionados a metas profissionais e financeiras, como consequência estabelece uma cultura que valoriza as emoções e o autoconhecimento através da vulnerabilidade, tratando sintomas depressivos como disparos para o desenvolvimento pessoal e profissional. As pessoas são estimuladas a buscarem soluções para déficits tratados como dificuldades pessoais, e estar em constante busca do bem-estar, e da qualidade de vida (Brinkmann, et. al., 2017).

A estimativa do bem-estar permite indagar a experiência individual, e essa compreensão consente em buscar contribuições para a melhoria da qualidade de vida das pessoas (Campos, 2016).

As situações de crise demandam respostas a problemas que fogem ao esperado, surgindo então possibilidades de desenvolvimento do potencial criativo, vencer desafios, encontrar soluções para problemas, buscar a autorrealização pessoal, fazer uso da intuição e imaginação, olhar um problema sob diferentes perspectivas (Santos, Gibim, \& Wechsler, 2020).

A autorregulação emocional é um aspecto de importância para a adequação dos sujeitos e exerce alta influência em seu desenvolvimento e saúde mental, composta por processos internos e externos que são responsáveis por monitorar, avaliar e alterar as reações emocionais, nos aspectos de intensidade e tempo. A regulação emocional beneficia o controle emocional, facilitando a adaptação, a competência social, o desempenho acadêmico e profissional. A criatividade e o otimismo são 
características que potencializam os resultados e o comportamento das pessoas em diferentes lugares e situações (Santos, Gibim \& Wechsler, 2020).

As experiências das pessoas são construídas socialmente por meio de crenças, culturas, pressuposições e expectativas, com isso passou a ser necessário analisar a realidade vivenciada pelos acadêmicos como uma forma de identificar, não somente fatores que podem gerar problemas durante o curso, mas também aspectos relacionados ao desenvolvimento psicossocial do estudante (Gonçalves, et al., 2018).

Torna-se atraente e aceitável pelo amplo público, aproximar-se de temas que conversam com demandas atuais da sociedade, assim, vem sendo utilizada em diferentes situações e aplicações, como no ensino, em organizações e no desenvolvimento pessoal. Em contrapartida, recriminam pela forma como ela pode potencializar a autocracia do pensamento positivo, porque entendem que esse discurso começa supervalorizar construtos relacionados ao bem-estar e abandonar os déficits ou aspectos negativos da saúde mental (Brinkmann, 2017).

Do mesmo modo, cabe analisar se o estilo de vida dos estudantes universitários envolve comportamentos pouco saudáveis que podem comprometer tanto a saúde quanto a qualidade de vida, pois este período de mudança no ensino pode mudar o estilo de vida relacionado aos hábitos alimentares, de dormir, práticas de exercícios físicos, consumo de álcool e até mesmo de outras drogas (Cortella, 2017).

A instituição tem como responsabilidade conhecer a realidade dos acadêmicos, pois desta forma poderão direcionar ações que visem ampliar a adaptação dos mesmos permitindo a integração dos cursos existentes e intervir em fatores na qualidade de ensino e aprendizagem ofertados por ela. Além disso, torna-se essencial avaliar como está sendo a satisfação acadêmica, de forma a garantir uma educação eficaz e de qualidade (Gonçalves et al., 2018).

Para obter uma vida equilibrada é necessário unir questões que diariamente atraia o interesse do acadêmico, assim como estudar em um curso que o aproxime de seus sonhos, que traga felicidade em frequentar as aulas e tirar o máximo de conhecimentos para a prática diária (Barros Filho \& Karnal, 2016).

Para a felicidade ser completa, as escolhas devem ser para si e nunca por razão de qualquer. Honra, prazer, inteligência e todas as virtudes deve ser escolhida para si, mas também devem ser escolhidas por causa da Felicidade, sob o pressuposto de que é através dela que se vive uma vida de felicidade e que ninguém deve ir à busca da felicidade por causa de qualquer uma das virtudes ou por causa de qualquer outra coisa (Aristotle, 2000).

Diante do exposto levanta-se o seguinte questionamento: O que é felicidade e a qual a percepção de bem-estar na visão acadêmica? Você faz planejamento para o futuro? Esse planejamento relaciona-se com a qualidade de vida?

Assim, o estudo em questão tem por objetivo, avaliar a percepção de felicidade e bem-estar de acadêmicos universitários.

\section{Material e Métodos}

Este estudo é uma pesquisa de campo de abordagem qualitativa e quantitativa, exploratório-descritivo. A população deste estudo foi composta pelos discentes matriculados no Instituto Educacional Santa Catarina/ Faculdade Guaraí-IESC/FAG no Estado do Tocantins, Brasil.

O caráter de pesquisa qualiquantitativa, conforme Pereira et al., (2018), refere à pesquisa que se encontra em medições nos estudos quantitativos ou de entrevistas e questionários nos estudos qualitativos ou estudos qualiquantitativa nos quais os resultados numéricos são complementados por resultados qualitativos.

O estudo foi realizado obedecendo aos princípios éticos da pesquisa com seres humanos, preconizados na Resolução n 466/2012 do Conselho Nacional de Saúde (Brasil, 2012). O projeto de pesquisa foi devidamente submetido à apreciação do 
Comitê de Ética em Pesquisa da Instituição Federal de Educação, Ciências e Tecnologia do Tocantins- IFTO, Palmas - TO, e obteve aprovação sob parecer $n^{\circ} 4.948 .923$.

A coleta de dados foi realizada no mês de setembro de 2021 utilizando como instrumento para o levantamento de dados questionário semiestruturado (14 perguntas) desenvolvidas pelos próprios autores.

Os questionários foram respondidos através da plataforma virtual Google Forms, por meio de um link repassado aos discentes de cada curso através de redes de comunicação pelos seus respectivos coordenadores.

\section{Resultados e Discussão}

A qualidade de vida dos acadêmicos sofre interferência de seu cotidiano. Observa-se que os estudantes passam a lidar com um novo cenário psicológico quando se deparam com ensino superior tendo em vista que este momento também representa o início de sua autonomia (Teixeira et al., 2008).

O ambiente universitário configura-se em um espaço de diversidades sociais, culturais, objetivos pessoais entre outras individualidades. Este trabalho tem como finalidade avaliar a satisfação e o nível de importância que os estudantes dessa universidade atribuem aos cursos de sua escolha, podendo esclarecer se a instituição avaliada está atendendo suas expectativas.

Participaram da pesquisa 104 acadêmicos do Instituto Educacional Santa Catarina/ Faculdade Guaraí- IESC/FAG de forma voluntária. A amostra foi constituída por $61 \%$ de acadêmicas do sexo feminino, $35 \%$ do sexo masculino e $5 \%$ declaravam-se de outro sexo, com idades variando $<20$ e $30>$ anos.

O questionário agregado aos acadêmicos foi desenvolvido por categorias que identificassem o nível de satisfação com o curso, qualidade de vida, e percepção de felicidade relacionada à instituição no município de Guaraí-TO.

A satisfação com a vida acadêmica proporcionar a prática interpessoal e a capacidade de decidir os problemas no meio acadêmico, relacionada com a adaptação aos novos ritmos de aprendizagem e avaliação.

Gráfico 1: Satisfação com o curso/ Planejamento para o futuro/ Orgulho da trajetória acadêmica.

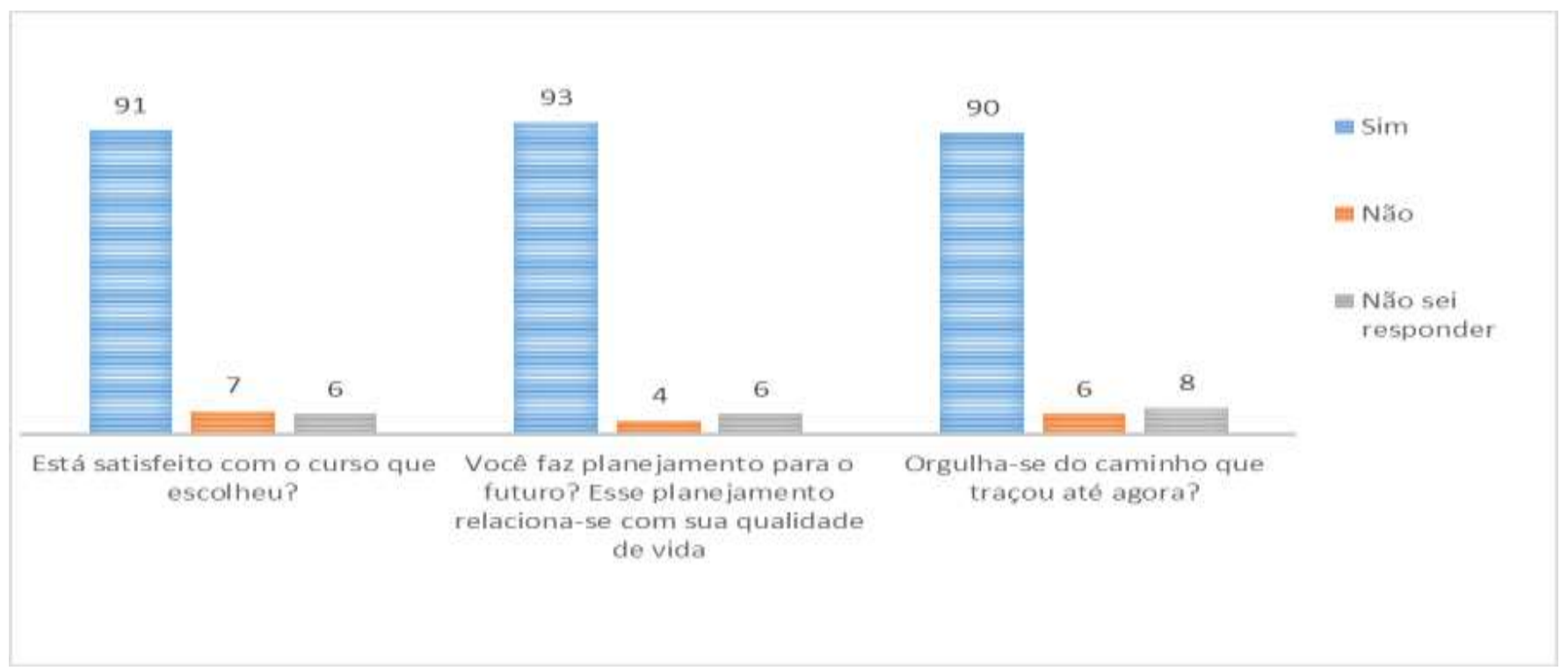

Fonte: Elaborado pelos autores (2021).

Observa-se no Gráfico 1, que apresenta a satisfação dos acadêmicos em relação a escolha de seu curso, onde 91 que representam $88 \%$ da amostra afirmaram estarem satisfeitos, seguido de 07 que corresponde a $7 \%$ não estão satisfeitos, e 06 equivalente a $6 \%$ não souberam responder. Em relação ao planejamento para o futuro, 93 (90\%) afirmam que planejam o 
futuro e que este mantem relação com sua qualidade de vida, enquanto 04 (4\%) dizem que não, e 06 (6\%) não souberam responder. No gráfico 01, é demonstrado ainda que 90 (87\%) se orgulham do caminho que traçaram até o momento, 06 (6\%) se declararam insatisfeitos e os outros 08 (8\%) não souberam responder.

A satisfação pessoal está catalogada com o quão os alunos estão automotivados com o curso, carreira e vida pessoal, de acordo com Bardagi \& Hutz (2010), satisfação de vida é um construtor que se refere à avaliação cognitiva que o indivíduo faz sobre sua qualidade de vida geral ou relativa a domínios como trabalho, lazer, amor, saúde, finanças, etc.

Gráfico 2: O lidar com emoções e apoio externo.

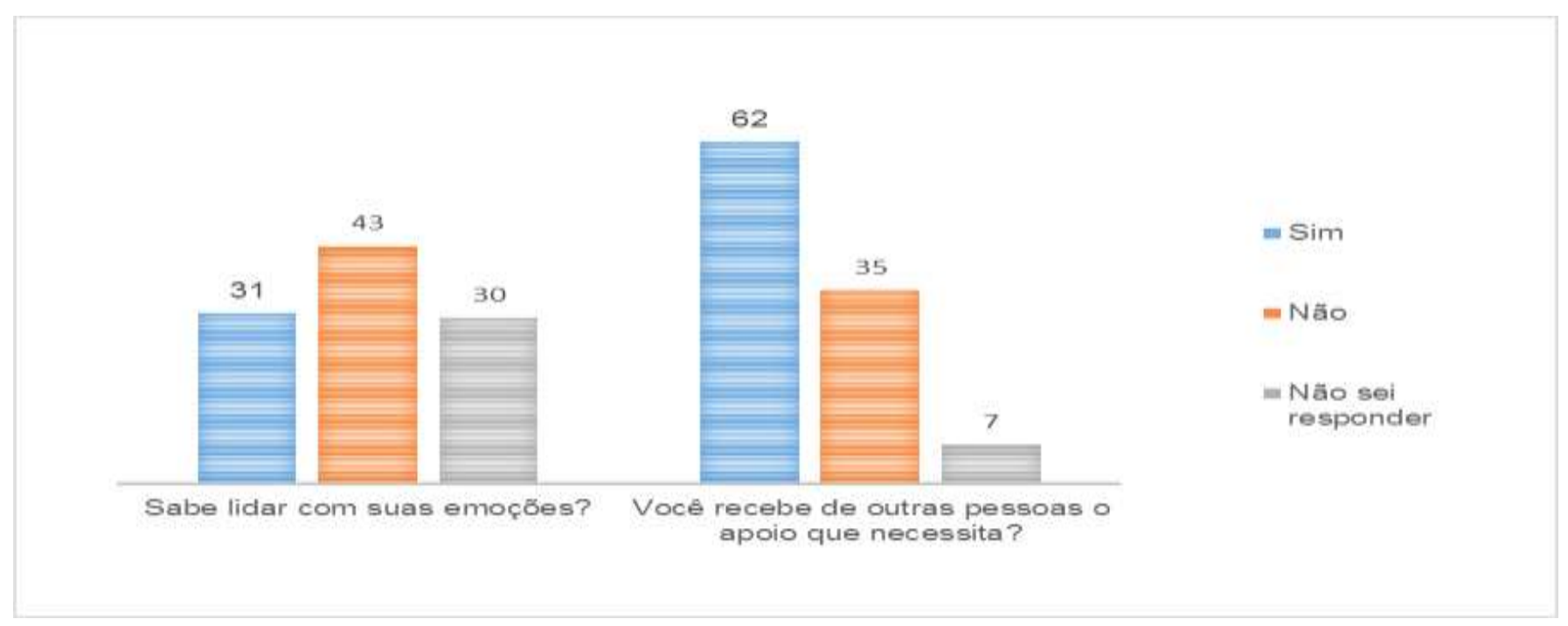

Fonte: Elaborado pelos autores (2021).

Na apreciação do Gráfico 2, é demonstrado que 31 acadêmicos (30\%) sabem lidar com suas emoções, enquanto que 43 acadêmicos (41\%) não conseguem lidar com suas emoções, e 30 (29\%) não souberam responder. É demonstrado ainda que 62 participante que corresponde à $60 \%$ afirmam que recebem de outas pessoas o apoio que necessitam, 35 dos que responderam equivalem à 34\% dizem que não, e restando 07 dos que responderam perfazendo 7\% não souberam responder.

A felicidade pode ser influenciável pela saúde física, mas somente uma mente saudável podem vivenciar este anseio, as duas estão muito conectadas. A saúde mental é muito importante para que as pessoas mantenham hábitos saudáveis e pratiquem atividades físicas. Ela também é importante para enfrentar os desafios diários. A felicidade em si é um conjunto desses fatores (Pollara, 2016).

Bardagi (2007), destaca a importância de avaliar os acadêmicos em diferentes períodos do curso, visando alcançar o desenvolvimento e amadurecimento individual durante o decorrer da graduação os acadêmicos podem apresentar características destintas, o vínculo de amizade, conteúdos e atividades podem estar associados com a satisfação acadêmica e segurança profissional.

Petrus (2001), entende o conceito a partir do pressuposto que ambiente social implica num conjunto de necessidades básicas das pessoas, em suas condições objetivas de vida, presentes em uma determinada área, tais como saúde, educação, cultura, lazer, alimentação, transporte, moradia, trabalho e da atitude subjetiva das pessoas habitantes dessa área frente a essas condições. Portanto, qualidade de vida não está ligada somente às emoções, mas também aos aspectos sociais. Em consequência, se tivermos uma boa interação entre as pessoas, também teremos um bom ambiente para a estabilidade psicológica e para o desenvolvimento das potencialidades dos indivíduos, resultando em uma boa qualidade de vida. 
Isso mostra que é preciso realizar um trabalho ostensivo diante dos dados encontrados. Um desafio da academia da IESC para trabalhar temática relacionado com o tema felicidade, adotar medidas em ações que ajudam os acadêmicos em diferentes dimensões envolvidas durante a formação, para que vivenciem e superem as adversidades do processo durante a graduação, e possa oferecer uma formação que valorize as capacidades do acadêmico e a qualidade de vida na educação, a importância da rede de apoio psicológico e física.

Gráfico 3: Auto avaliação da qualidade de vida.

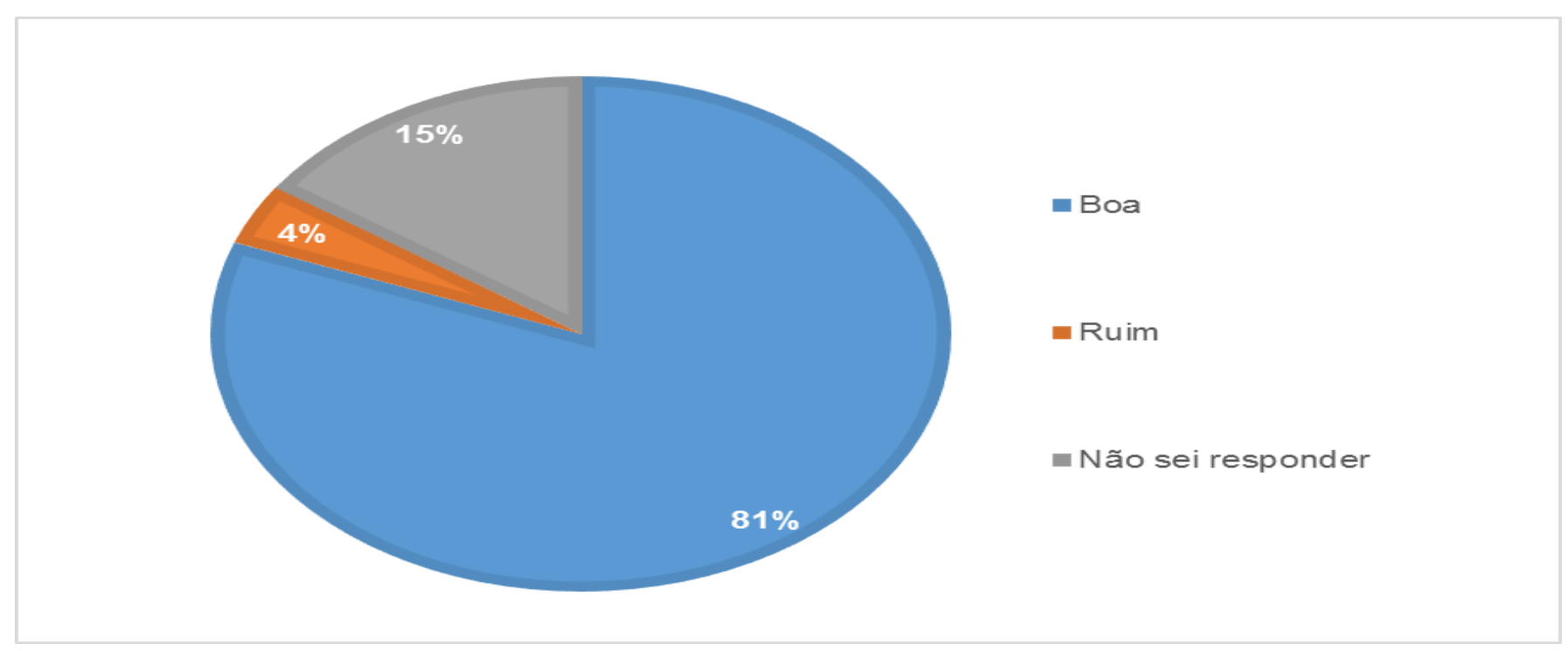

Fonte: Elaborado pelos autores (2021).

O Gráfico 3, mostra que em relação a como avaliar sua qualidade de vida, 84 (81\%) refere-se boa, 04 (4\%) dizem ser ruim, e $16(15 \%)$ não souberam responder. Esta leva-nos a refletir sobre o objeto saúde, que é um conceito em construção, dinâmico, que depende dos valores sociais, culturais e históricos, buscando uma relação harmoniosa para se viver com qualidade. A nova concepção de saúde deixa de ser apenas ausência de "doença", mas refere-se ao bem-estar e qualidade da vida.

Atualmente a qualidade de vida vem sendo discutida em diversos ambientes, em vista disso acarreta desafios para as políticas e as práticas da área da saúde. Um dos ambientes capazes de se explorar e analisar os fatores que podem entusiasmar a qualidade de vida é a educação superior (Seildl \& Zannon, 2004).

Qualidade acadêmica é definida como “[...] a capacidade de produção original de conhecimento, da qual depende intrinsecamente à docência" (Demo,1985, p. 35). O ensino superior requer cultivar a criatividade científica que é baseada na pesquisa. Portanto, a qualidade do ensino superior depende da capacidade de o professor transmitir o conhecimento que ele próprio construiu por meio de suas atividades de pesquisa e de orientar os alunos a dar tratamento teórico, pesquisar e apresentar soluções práticas a problemas específicos da sociedade.

No entanto, verificou-se que qualidade de vida, estudados pela Psicologia Positiva estão relacionados com a conduta acadêmica, demonstrando-se que os acontecimentos nesta área particular estão associados a uma vida psicologicamente rica e saudável, entre estudantes universitários. Como é sabido que certas condições às quais os indivíduos estão expostos relacionam-se diretamente com a felicidade e o bem-estar subjetivo, é possível que mudanças planejadamente impostas ao estilo e características de vida dos universitários venham a influenciar os níveis de bem-estar e felicidade experimentados e, consequentemente, determinar condutas acadêmicas mais desejáveis (Seligman, 2004). 
Para que os acadêmicos consigam o sucesso faz se necessário que lhes sejam proporcionadas condições adequadas para o desenvolvimento e desempenho de suas atividades. As coisas necessárias no geral inclui transporte, habitação, lazer, trabalho, família, espiritualidade, e levando em consideração que cada acadêmico tem sua individualidade, esse conceito junta não só bens materiais, mas outras dimensões são necessárias para que os mesmos alcancem uma qualidade de vida.

Bardagi \& Hutz (2005), mostram a necessidade de investir em uma rede de suporte aos acadêmicos devido ao fato de que é possível observar uma baixa qualidade de vida durante todo o período de graduação, devendo ainda promover a autoconfiança nesses estudantes melhorando sua própria capacidade para resolver problemas, assim por meio de orientação torna-se possível a prevenção dos riscos que a rotina acadêmica pode produzir tanto na dimensão física, emocional e cognitiva.

Gráfico 4: De que depende a felicidade na visão dos acadêmicos.

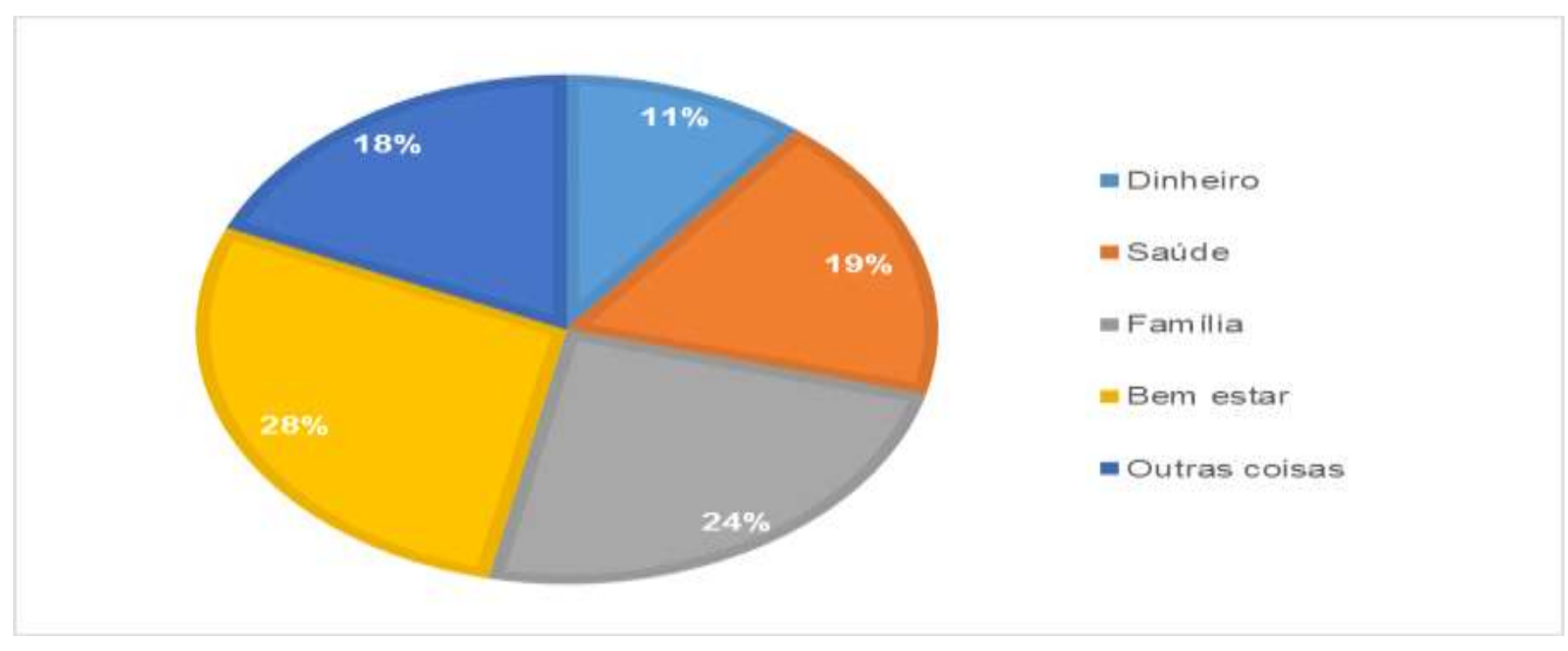

Fonte: Elaborado pelos autores (2021).

A partir do Gráfico 4, observa-se que a maioria dos participantes 29 (28\%) definiram felicidade advinda do bem estar, seguido de 25 (24\%) pela família, 19 (19\%) pela saúde, 19 (18\%) dos participantes afirmaram que sua felicidade depende de outras coisas, enquanto $11(11 \%)$ relacionaram a felicidade ao dinheiro. Os dados expostos mostram claramente que a concepção de bem estar passa prioritariamente pela satisfação de exigências relativas a saúde, família, dinheiro, família e outros.

Nesta pesquisa acredita-se que a felicidade é a busca continua do bem-estar, o equilíbrio emocional e racional, em conter os pensamentos, procurar ter uma vida com entusiasmo e evitar os vícios, conhecer a si mesmo, em do que é capaz, procurar continuamente melhorar. A busca desenfreada de felicidade individual é sinal de que grande parte das pessoas tomou um rumo equivocado. A sociedade não pode desenvolver sem compartir de metas, objetivos, de bem comum. 
Gráfico 5: A felicidade através do dinheiro e o poder de compra.

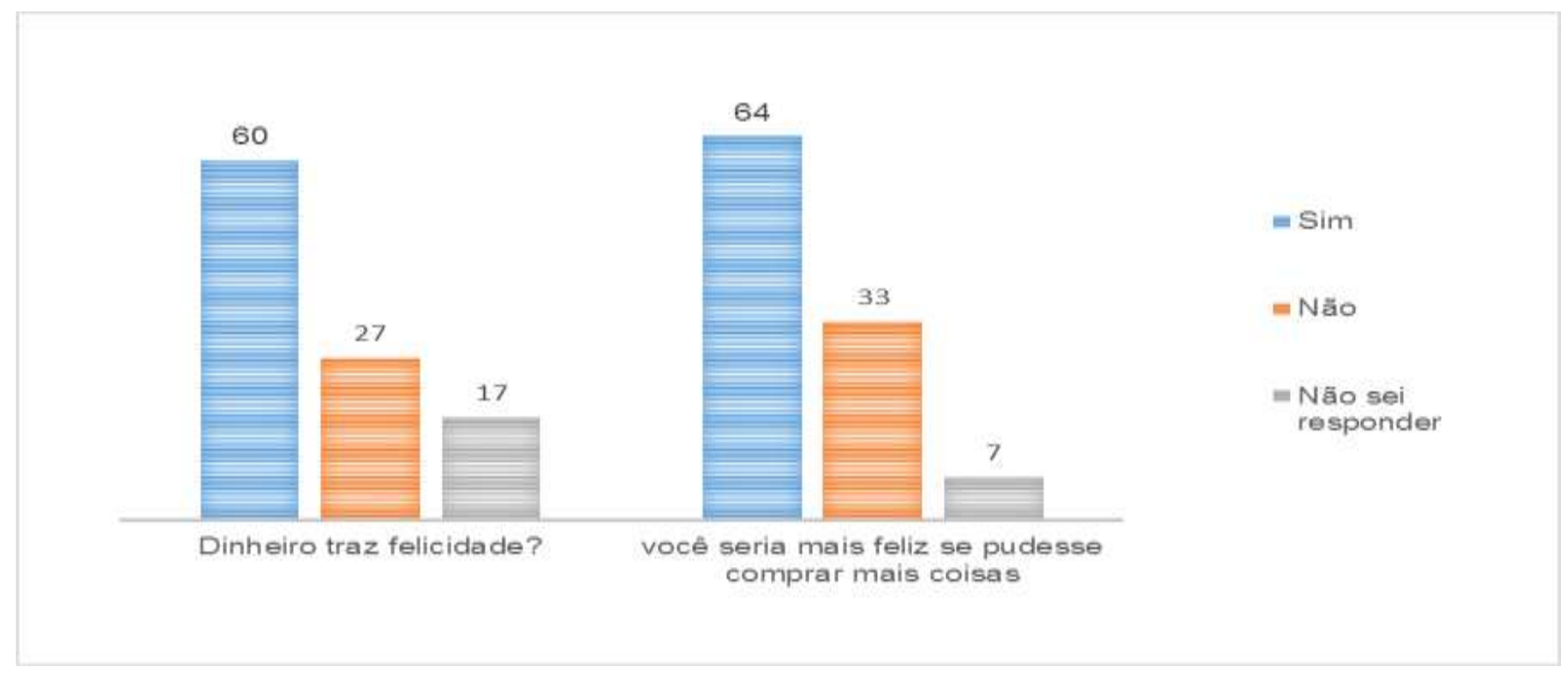

Fonte: Elaborado pelos autores (2021).

O Gráfico supracitado, apresenta a felicidade dos acadêmicos em relação ao dinheiro, sendo que 60 ao qual representa $58 \%$ dos participantes afirmam que o dinheiro traz felicidade, seguido de 27 que corresponde a $26 \%$ afirmam que não e 17 equivalente a $16 \%$ não souberam responder. Em relação a pergunta: você seria mais feliz se pudesse comprar mais coisas, cerca de 64 (62\%) afirmaram que sim, enquanto 33 (32\%) disseram que não, e 07 (7\%) não souberam responder.

A felicidade não se compra, se vive, e as pessoas estão em um ciclo onde a opção sempre é trabalhar e aumentar seu capital, e acabam se esquecendo do equilíbrio. É correto afirmar que os acadêmicos vivem no piloto automático do dia a dia, e pela monotonia escolhem carreiras e profissões somente porque os pais ou a sociedade determinam ser a porta para o sucesso e ganho de dinheiro, se separando do que realmente lhe traz felicidade (Ben-Shahar, 2019).

De acordo com a análise afirmamos que mesmo tendo um alto índice de participantes dizendo ser mais felizes se pudesse comprar mais coisa, o economista Richard Easterlin apresentou um questionamento que passou a ser conhecido como o "Paradoxo de Easterlin". Ele dizia o seguinte: "Em todas as sociedades, mais dinheiro para o indivíduo tipicamente significa mais felicidade para o indivíduo. No entanto, aumentar a renda de todos não aumenta a felicidade de todos" (Easterlin, 1973, p. 4).

O dinheiro revelou-se como meio necessário para se viver, considerando-se que faz parte da condição existencial estudar, trabalhar e planejar para adquiri-lo. Na percepção dos acadêmicos, ele não foi mencionado como o objetivo maior da vida, como o plano mais elevado a ser almejado, mas um meio, um caminho, um instrumento para viver bem e feliz. 
Gráfico 6: Com que frequência tem sentimentos negativos tais como tristeza, desespero ansiedade ou depressão.

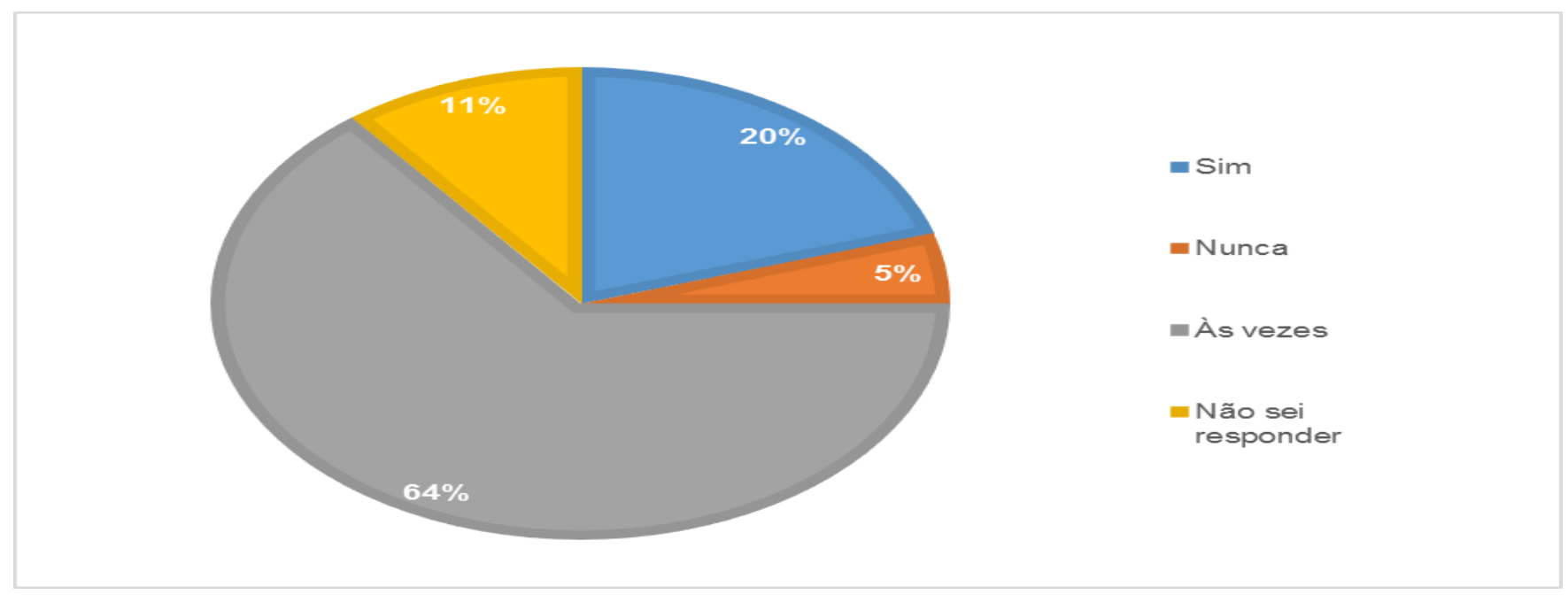

Fonte: Elaborado pelos autores (2021).

No Gráfico 6, apresenta que 21 que representam 20\% dos acadêmicos apresentaram sentimentos negativos tais como tristeza, desespero, ansiedade ou depressão, 67 equivalente a $64 \%$ afirmam ter esses sentimentos as vezes, 05 sendo $5 \%$ dos entrevistados referem nunca ter apresentado esses sentimentos e 11 que corresponde $11 \%$ não souberam responder.

De acordo com Albuquerque \& Tróccoli (2004), as emoções negativas estão relacionadas a sentimentos desagradáveis, como angústia, ansiedade, aborrecimento, estresse, tensão, pessimismo, medo, tristeza entre outros sentimentos, o que parece estar bastante presente na percepção afetiva desses estudantes.

$\mathrm{Na}$ procura de uma graduação, muitos jovens deslocam-se de suas cidades e passam a residir longe dos amigos e familiares, um grande fator que pode interferir na adaptação. Conhecer e conviver com novas pessoas abrange conceitos inovadores, quando vínculos de amizades não se desenvolve os acadêmicos podem somar apenas com seus próprios recursos e o apoio das redes constituídos antes do ingresso a universidade (Diniz \& Almeida, 2006).

Com a realização desta pesquisa e percepção cotidiana, analisamos que a pressão para aprender, a exigência de alto rendimento, a quantidade de informações, a falta de tempo para atividades, são causas que podem conduzir ao aparecimento de sintomas depressivos entre os acadêmicos. Mesmo em todas as adversidades percebemos que cerca de $70 \%$ dos entrevistados recebem de outras pessoas o apoio que necessitam, e 34\% não recebem nenhum tipo de apoio.

A formação universitária exige do acadêmico um esforço maior do que aquele com o qual estava acostumado no ensino médio. Há prazos mais rigorosos para entrega de trabalhos, relatórios de estágio, seminários que devem ser apresentados, provas, além do próprio estágio e o Trabalho de Conclusão de Curso, que deve ser entregue e defendido oralmente. Nesse sentido, a vida do acadêmico, principalmente no último período, está sujeita a um turbilhão de reações emocionais diversas, constituindo-se, assim, num período de maior estresse (Assis, 2013). 
Gráfico 7: Alcance de metas estipuladas/ Coisas necessárias para aproveitar a vida.

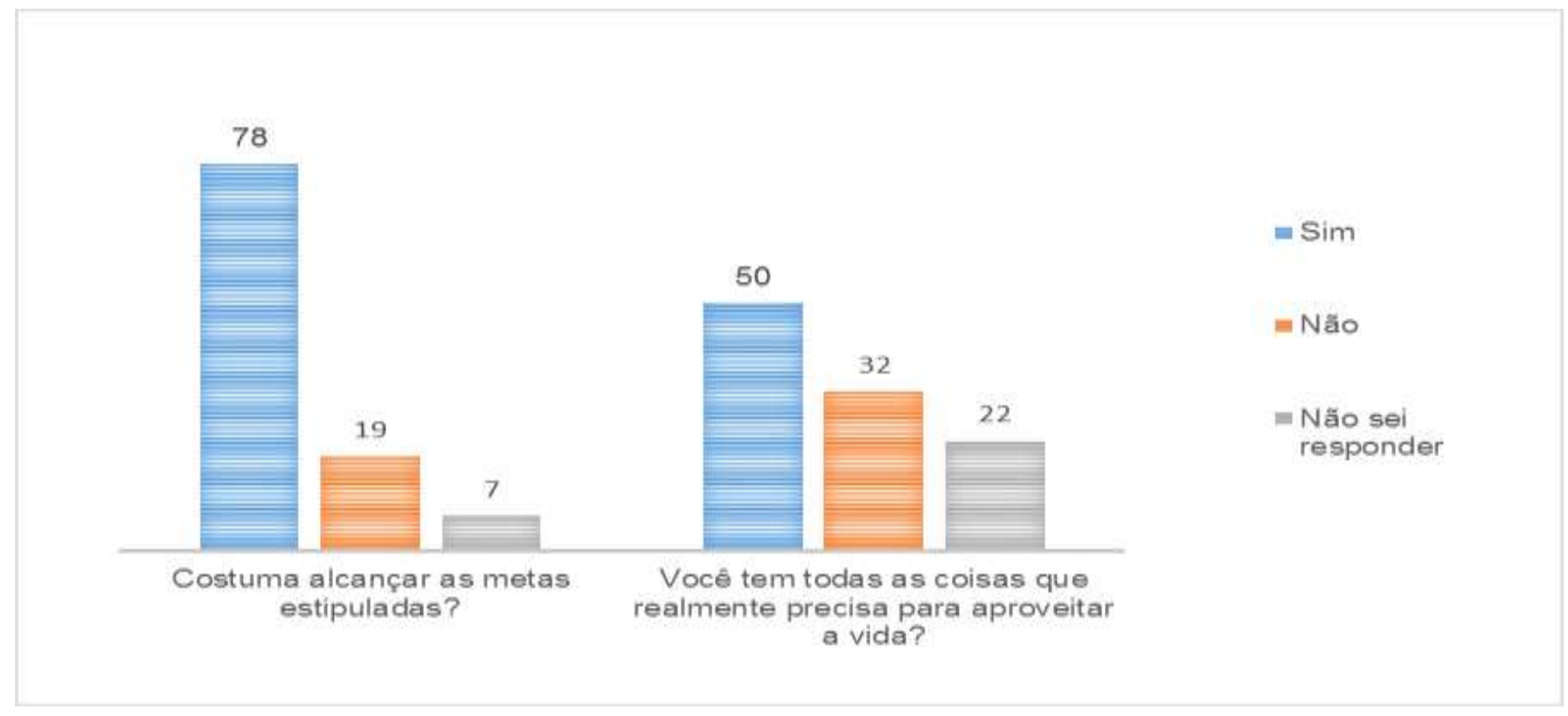

Fonte: Elaborado pelos autores (2021).

O Gráfico 7, mostra que 78 participantes que corresponde a 75\% afirmaram que costumam alcançar as metas estipuladas, 19 que representam $18 \%$ não conseguem alcançar suas metas, e 07 equivalente $7 \%$ não souberam responder. Neste gráfico os resultados ainda mostram que 50 (48\%) afirmam ter todas as coisas que realmente precisa para aproveitar a vida, no entanto, $32(31 \%)$ afirmam não ter obtido todas as coisas que realmente precisam, já os outros $22(21 \%)$ não souberam responder.

A felicidade acadêmica é expressa na forma como os alunos enxergam a universidade e como percebem o cenário de aprendizagem, felicidade acadêmica tem relação com a confirmação ou não das expectativas dos estudantes com a realidade da instituição sendo que quanto mais esse índice de felicidade for alcançado melhor para o aluno e para universidade. Além disso, ela está interligada com a qualidade de aprendizagem dos estudantes e com a forma como eles avaliam o ambiente estudantil (Assis, 2013).

As metas e realizações são caracterizadas como um conjunto de pensamentos e emoções, além da religiosidade e dos propósitos. Elas têm relação com as expectativas e anseio dos alunos relacionadas as atividades acadêmicas, constituindo-se em diferentes maneiras de enfrentar os desafios, que afetam o modo pelo qual os estudantes abordam as tarefas diárias, para conseguir o sucesso, evitar o fracasso, para mostrar ou desenvolver a própria competência. As metas desfrutam de certa estabilidade, mas não são tão estáveis como os traços de personalidade. Elas podem ser influenciadas tanto por aspectos psicológicos, quanto pelas ações dos docentes.

No contexto acadêmico, as metas ou objetivos orientados para a aprendizagem relacionam-se com estratégias e estudo mais eficazes, com um rendimento acadêmico superior. Contudo, há estudos evidenciam que a diversidade de metas acadêmicas apresenta correlações positivas com a regulação do esforço, o valor dado às tarefas acadêmicas, a autorregulação metacognitiva, a autoeficácia ou crenças de controlo e a gestão do tempo e ambiente de estudo, podendo haver um ajustamento do tipo de metas definidas em função da situação ou do contexto de aprendizagem com que o aluno se confronta (Miranda, 2009). 


\section{Considerações Finais}

Os resultados mostraram que os participantes avaliaram sua satisfação, bem-estar e felicidade de modo bastante positivo. A busca desenfreada de felicidade individual é sinal de que grande parte das pessoas tomou um rumo equivocado. A sociedade não pode prosperar sem compartilhar metas, objetivos, de bem comum.

Quando a única meta é alcançar o melhor pra si mesmo, a vida torna-se estressante, solitária e abre espaço para a infelicidade. Deve-se procurar sempre agregar algo ao bem estar ou mitigar um pouco as suas dores, para que tenha paz e a alegria.

Pode-se concluir que a felicidade é a busca continua do bem estar, o equilíbrio emocional e racional, em dominar os pensamentos e paixões, procurar ter uma vida com virtude e evitar os vícios, conhecer a si mesmo, do que é capaz, procurar sempre melhorar.

Por fim, é importante dizer que a pesquisa ajudou a conhecer o perfil acadêmico de maneira subjetiva e individual, no entanto, a ciência e a pratica desta teoria são muito amplas, e o objetivo maior e principal é alcançar o entendimento da felicidade acadêmica e como efeito ajudar os indivíduos, familiares e comunidades em geral a prosperarem e desenvolverem suas forças e virtudes, de modo a atingir a felicidade o bem estar.

Neste sentido, este trabalho procura determinar índices de satisfação, felicidade, bem estar, apoio emocional, em amostras de universitários, e sua relação com o comportamento acadêmico, a conclusão de que níveis mais altos de felicidade e satisfação estariam relacionados a comportamentos mais positivos no contexto da IESC/FAG.

\section{Referências}

Adriana, C. P. (2016). A cadeira vazia no grupo. Jornal de Psicanálise. Vol. 48, nº 88, p. 145-152, São Paulo dez. 2016.

Albuquerque, A. S., \& Tróccoli, B. T. (2004). Desenvolvimento de uma escala de bem-estar subjetivo. Psicologia: teoria e pesquisa, 20 (2), 153-164. http://www.scielo.br.

Assis, C. L.; Silva, A. P. F.; Lopes, M. S.; Silva, P. C. B.; Santini, T. O. (2013). Sintomas de estresse em concluintes do curso de psicologia de uma faculdade privada do norte do País. Mudanças - Psicologia da Saúde, v. 21, n. 1, p.23-28.

Aristotles, C. R. (2000). Nicomachean Ethies (Cambridge Texts in the History of Philosophy). Cambridge: Cambridge University Press, 2000.

Aristóteles. (2009). Ética a Nicômaco. Trad. Antônio de Castro Caeiro. São Paulo: Editora Atlas, 2009.

Assis, R. C. C. \& Alves, M. A. (2020). Satisfação dos estudantes de cursos de gestão de uma instituição Superior Pública. ForScience, 8 (1), e 0065 -e00656.

Bardagi, M. P. \& Hutz, C. S. (2005). Evasão universitária e serviços de apoio ao estudante: uma breve revisão da literatura brasileira. Psicologia Revista, São Paulo, v. 14, n. 2, p. 279-301.

Bardagi, M. P. (2007). Evasão e comportamento vocacional de universitários: estudos sobre o desenvolvimento de carreira na graduação. 2007.242 f. Tese (Doutorado em Psicologia) - Universidade Federal do Rio Grande do Sul, Porto Alegre.

Bardagi, M. P \& Hutz, C. S. (2010). Satisfação de vida, comprometimento com a carreira e exploração vocacional em estudantes universitários. Arquivos Brasileiros de Psicologia, v. 62, n. 1, 2010.

Barros Filho, C. de \& Karnal, L. (2016). Felicidade ou morte. 13. ed. Campinas: Papirus 7 Mares, 2016.

Ben-Shahar, Tal. (2019). O professor de Harvard que ensina a ser feliz.

Betto, F.; Boff, L.; \& Cortella, M. S. (2016). Felicidade foi-se embora? Petrópolis: Vozes; 2016.

Boni, R. B. de. (2020). Websurveys nos tempos de COVID-19. Cad. Saúde Pública, Rio de Janeiro, Pag. 36, 2020.

Blassmann, C. B. (2012). Perpectivas profissionais e planejamento de carreira dos estudantes de administração da Universidade Federal do Rio Grande do Sul. Porto Alegre. 2012.

Brasil. Ministério da Saúde. (2012). Ministério da Educação. Manual Instrutivo - Programa Saúde na Escola. Brasília, 2012.

Brinkmann, S. (2017). Strand Firm: Resisting the self-improvement craze, UK: Politu Press, 2017.

Campos, D. C. (2016) Vitimização e Revitimização em Estudantes Universitários: influência de fatores individuais e sociais. Pontifícia Universidade Católica de Goiás, Goiânia. p. 69-76, 2016. 
Cortella, M. S. (2017). Viver em paz para morrer em paz: e você não existisse, que falta faria? Pag. 13-16, 2017.

Davok, D. F. \& Bernard, R. P. (2016). Avaliação dos índices de evasão nos cursos de graduação da Universidade do Estado de Santa Catarina - UDESC. Revista Avaliação, Campinas; Sorocaba, SP, Pag. 503-21, 2016.

Demo, P.; (1985). Ciências sociais e qualidade. Avaliação, Campinas; Sorocaba, SP, p. 505-513, 1985.

Diniz, A. M. \& Almeida, L. S. (2006). Adaptação à universidade em estudantes de primeiro ano: Estudo diacrónico da interação entre o relacionamento com pares, o bem-estar pessoal e o equilíbrio emocional. Análise Psicológica, Lisboa, v. 1, n. 24, p. 29-38, 2006.

Easterlin, R.A. (1973). "Does Money Buy Happiness?". The Public Interest, no 30, pp. 3-10.

Ferry, L. (2018). Sete maneiras de ser feliz: como viver de forma plena. Melo JAD, tradutor. Rio de Janeiro: Objetiva; 2018.

Gracioso, J. (2010). Interioridade e filosofia do espírito nas confissões de Santo Agostinho, 131 Tese (Doutorado) - Faculdade de Filosofia, Letras e Ciências Humanas, Universidade de São Paulo. São Paulo, 2010.

Gonçalves, E. R., et al., (2018). Programa Universitário Por Um Dia: conhecendo a Escola de Enfermagem de Ribeirão Preto, Pag. 22 , 2018.

Lenoir, F. (2016). Sobre a felicidade: uma viagem filosófica. Dos Reis VL, tradutor. Rio de Janeiro: Objetiva; 2016.

Lobos, G., Lapo, M., \& Schnettler, B. (2016). In the choice between health and money, health comes first: an analysis of happiness among rural Chilean elderly. Cad Saúde Pública. 2016;32(5):1-12.

Manson, M. (2017). A sutil arte de ligar o f*da-se. Rio de Janeiro: Intrínseca, Pag. 20, 2017.

Matz, S. C., Gladstone, J. J., \& Stillwell, D. (2016). Money buys happiness when spending fits our personality. Psychol Sci. 2016;27(5):715-25

Pereira, A. S., et al., (2018). Metodologia da pesquisa científica. [e-book]. Santa Maria. Ed. UAB/NTE/UFSM.

Minayo, M. C. S. (2016). O desafio do conhecimento: pesquisa qualitativa em saúde. 14. ed. São Paulo: Hucitec; 2016.

Miranda, L., \& Almeida, L. S. (2009). As metas académicas como operacionalização da motivação do aluno. Educação Temática Digital, 10, 36-61.

Noronha, A. P. P., \& Barbosa, A. J. G. (2016). Forças e Virtudes: Escala de Forças de caráter. In C. S. Hutz (Org.), Avaliação em Psicologia Positiva: Técnicas e Medidas (pp. 21-43). São Paulo: CETEPP.

Pereira, C. R. (2017). Pelo direito de não ser feliz: uma breve análise filosófica, sociológica e existencial sobre a ditadura da felicidade. Trilhas filos. 2017;10(2):47-69.

Petrus, M. R. (2001). Emigrar de Angola e Imigrar no Brasil: Jovens imigrantes angolanos no Rio de Janeiro: histórias, trajetórias e redes sociais. 250fls. Dissertação de Mestrado, Instituto de Pesquisa e Planejamento Urbano. IPPUR, Universidade Federal do Rio de Janeiro, Rio de Janeiro, 2001.

Santos, M. C., Gibim, Q.G.M.T., \& Wechsler, S.M. (2020). Relação entre criatividade e otimismo: percepção de adultos. Revista Ibero-Americana de Criatividade e Inovação, Pag. 41-50, 2020.

Seligman, M. (2004). Felicidade autêntica: usando a nova Psicologia Positiva para a realização permanente. Rio de Janeiro: Objetiva.

Seidl, E. M. F., \& Zannon, C. M. L. C. (2004). Qualidade de vida e saúde: aspectos conceituais e metodológicos. Caderno de Saúde Pública, Rio de Janeiro, v. 20 , n. 2 , p. $580-588$.

Teixeira, M. A. P., et al., (2008). Adaptação à universidade em jovens calouros. Revista Semestral da Associação Brasileira de Psicologia Escolar e Educacional, São Paulo, v. 12, n. 1, p. 185-202.

Who. World Health Organization. (1946). Constitution of the World Health Organization. Basic Documents. WHO. Genebra.

Zenorini, R. P. C., Santos, A. A. A., \& Bueno, J. M. H. (2003). Escala de avaliação das metas de realização: estudo preliminar de validação. Avaliação Psicológica, Porto Alegre, v. 2, n. 2, p. 165-173. 